\title{
Delay to formalin fixation effect on breast biomarkers
}

\author{
Thaer Khoury ${ }^{1}$, Sheila Sait ${ }^{2}$, Helena Hwang ${ }^{1}$, Rameela Chandrasekhar ${ }^{3}$, Gregory Wilding ${ }^{3}$, \\ Dongfeng Tan ${ }^{4}$ and Swati Kulkarni ${ }^{5}$ \\ ${ }^{1}$ Department of Pathology, Roswell Park Cancer Institute, Buffalo, NY, USA; ${ }^{2}$ Department of Cytogenetics, \\ Roswell Park Cancer Institute, Buffalo, NY, USA; ${ }^{3}$ Department of Biostatistics, Roswell Park Cancer Institute, \\ Buffalo, NY, USA; ${ }^{4}$ Department of Pathology MD-Anderson Cancer Center, Houston, TX, USA; ${ }^{5}$ Department \\ of Surgical Oncology, Roswell Park Cancer Institute, Buffalo, NY, USA
}

Delay to formalin fixation may invalidate hormone receptors and HER2 analyses. Invalid results of tumor markers could significantly alter the type of adjuvant therapy a patient receives and potentially impact outcome. The purpose of this study was to determine the effects of progressive delay to formalin fixation on breast cancer biomarkers. Ten palpable invasive breast cancers were resected and underwent immediate gross evaluation. For each case, the procured tumor was divided into eight parts and consecutively fixed after 0,10 , $30 \mathrm{~min}, 1,2,4$, and $8 \mathrm{~h}$; one section was kept in saline and stored overnight at $4 \mathrm{C}$. Two tissue microarray blocks were constructed. Estrogen and progesterone receptors and HER2 immunohistochemistry and fluorescence in situ hybridization were carried out. Statistical analyses including non-parametric sign test, exact McNemar's test and Page's $L$ test were used. All 10 cases were invasive ductal carcinomas. $Q$ score $\geqslant 6$ was identified in five cases for estrogen receptor and four for progesterone receptor. Mean $\mathrm{Q}$ score started to decline at the $\mathbf{2 h}$ mark for estrogen receptor and $1 \mathrm{~h}$ mark for progesterone receptor. Lowest score was at $8 \mathrm{~h}$ mark for estrogen receptor and overnight for progesterone receptor. HER2 fluorescence in situ hybridization started to be compromised for interpretation at the $1 \mathrm{~h}$ mark and became statistically significant at the $2 \mathrm{~h}$ mark $(P<0.03)$. To avoid delay to formalin fixation as a factor negatively affecting on breast biomarkers, we recommend not to delay formalin fixation for more than $1 \mathrm{~h}$ and not to store specimens overnight.

Modern Pathology (2009) 22, 1457-1467; doi:10.1038/modpathol.2009.117; published online 4 September 2009

Keywords: breast cancer; biomarkers; delay to formalin fixation

Immunohistochemical analysis is the standard detection method for evaluating estrogen and progesterone receptors expression levels in invasive breast carcinoma cells. Consistent and accurate estrogen and progesterone receptors results are important because they are an integral part of therapeutic decision making. ${ }^{1-3}$ The decision to treat some women with endocrine therapy for up to 10 years is dependent on the results of these tests. The 'Ad hoc' consensus committee has implemented detailed recommendations on estrogen receptor testing by immunohistochemistry. ${ }^{4}$ For HER2, two methods are used and recommended by all current

Correspondence: Dr T Khoury, MD, Department of Pathology, Roswell Park Cancer Institute, Elm and Carlton streets, Buffalo, NY 14263, USA.

E-mail: thaer.khoury@roswellpark.org

Received 3 February 2009; revised and accepted 27 April 2009; published online 4 September 2009 national testing guidelines: immunohistochemistry analysis for the detection of protein expression and fluorescence in situ hybridization, a quantitative method for detection of gene amplification. ${ }^{5,6}$ Given the excellent response rate, ${ }^{7,8}$ significant prognostic value ${ }^{9-12}$ potential cardiac morbidity ${ }^{13,14}$ and high cost, ${ }^{15}$ it would be of great value to accurately determine HER2 amplification status. To insure proper evaluation, the American Society of Clinical Oncology and the College of American Pathologists (ASCO-CAP) have implemented criteria for HER2 evaluation by both methods. ${ }^{16}$

Most studies have investigated the impact of prolonged formalin fixation ${ }^{17-19}$ or the difference in breast cancer biomarker expression between needlecore biopsy and excisional biopsy. ${ }^{20}$ Although the 'Ad hoc' committee has set recommendations regarding estrogen receptor testing, limited reports have been published evaluating the effect of delay to formalin fixation on estrogen receptor and 
progesterone receptor status by immunohistochemistry. ${ }^{4,21}$ Moreover, to date no study investigating the effect of delay to formalin fixation on HER2 immunohistochemistry and fluorescence in situ hybridization has been published. In our study, we investigated the effect of delay to formalin fixation on all three of the most clinically relevant breast cancer biomarkers.

\section{Materials and methods}

\section{Specimen Collection and Processing}

Women with palpable breast cancers who had not received previous neoadjuvant therapy were eligible. Only those women who had a surgical lumpectomy were included in the study. Patients who underwent needle localization before surgical resection requiring post-excisional imaging and women undergoing a mastectomy were excluded in an attempt to keep tumor ischemia time consistent. As post-fixation time variation affects the status of breast estrogen and progesterone receptors, patients were scheduled for surgery at roughly the same time and samples were received between 0900 and 1000 hours. As per standard procedure, the orienting sutures were placed in the specimen when it was still in situ. Once the specimen was resected they were sent immediately from the operating room to the pathology department through the pneumatic tube system. Times of the resection in the operating room, and time of the first sample $(0 \mathrm{~min})$ were recorded. This time ranged from 2-5 min. Specimens were immediately grossly examined and dissected. Fresh tumor was procured and divided into eight parts, each measuring at least $3 \mathrm{~mm}$. The first part that was fixed in neutral-buffered formalin (10\% vol/formalin in water; $\mathrm{pH} 7.4$ ) was considered the 0 min specimen. The rest of the tissues were fixed after $10 \mathrm{~min}, 30 \mathrm{~min}, 1 \mathrm{~h}, 2 \mathrm{~h}, 4 \mathrm{~h}, 8 \mathrm{~h}$ and one sample was stored overnight at $4^{\circ} \mathrm{C}$. Tumor/ formalin proportion was above 20 times for each sample. Before being fixed, the tissue samples were held in $0.9 \% \mathrm{NaCL}$, with Osmolality $308 \mathrm{mOsmol} / \mathrm{l}$ to closely resemble tumor microenvironment. The overnight specimen was kept in the same solution at $4^{\circ} \mathrm{C}$ starting at $0 \mathrm{~min}$ to resemble some practices where specimens are kept in the operating room and transferred the following day to the pathology department for processing.

To avoid overfixation, $0 \mathrm{~min}$ through $8 \mathrm{~h}$ specimens were processed after roughly $24-32 \mathrm{~h}(0 \mathrm{~min}$ specimen processed after $32 \mathrm{~h}$, and $8 \mathrm{~h}$ specimen processed after $24 \mathrm{~h}$ ), and overnight specimen was processed after roughly $12 \mathrm{~h}$. All specimens were processed uniformly in the same manner as the clinically submitted specimens.

\section{Tissue Microarray Construction}

Eight tissue blocks from each case corresponding to each fixation time along with one clinically submitted tumor and one normal representative as controls were used for constructing the tissue microarrays. Two tissue microarrays were assembled using a Beecher tissue puncher and array system (Beecher Instruments, Silver Spring, MD). For each block, four 0.6-mm core samples were acquired and assembled in the receiving tissue microarray block. One Hematoxylin and Eosin slide from each block was prepared and reviewed to confirm presence of invasive tumor.

\section{Immunohistochemistry}

Estrogen receptor (clone 1D5, DAKO, with 1:100 dilution and TRS/Vector antigen retrieval), progesterone receptor (PgR636, DAKO, with dilution 1:100 and TRS/Steamer antigen retrieval) and HER2 (rabbit polyclonal, DAKO, prediluted with epitope retrieval solution) were performed. Sections were cut at $5 \mu \mathrm{m}$, placed on charged slides and dried in a $60^{\circ} \mathrm{C}$ oven for $1 \mathrm{~h}$. Upon return to room temperature, the slides were deparaffinized in three changes of xylene and rehydrated using graded alcohols. Endogenous peroxidase activity was quenched with aqueous $3 \%$ hydrogen peroxide for $15 \mathrm{~min}$ and washed with phosphate-buffered saline with $0.05 \%$ Tween 20 (PBS-T). Antigen retrieval was then performed. After a PBS-T wash, casein $0.03 \%$ (in PBS-T) was used as a block for $30 \mathrm{~min}$ and then the primary antibody was applied to the slides and left for 30-60 min. A PBS-T wash was followed by the biotinylated secondary antibody for $30 \mathrm{~min}$. The PBS-T was followed by the streptavidin complex for $30 \mathrm{~min}$. PBS-T was used as a wash and the Chromagen 3,3'-diaminobenzidine (DAKO, Carpenteria, CA) was applied for $5 \mathrm{~min}$ (the color reaction product was brown). The slides were counterstained with Hematoxylin.

One representative full section from clinically submitted tumor tissue was used to perform immunohistochemistry of all markers to assess the uniformity and distribution of the staining.

Cores from the same sample were collectively scored. Estrogen and progesterone receptor staining was assessed semiquantitatively on the full clinically submitted section by using the Q-score method. This method incorporates intensity and distribution of reactivity. ${ }^{17}$ Intensity was scored as follows: 0, negative (no staining of any nuclei at high magnification); 1, weak (staining visible only at high magnification); 2, moderate (staining readily visible at low magnification); or 3, strong (staining strikingly positive at low magnification). The proportion of stained cells was scored as follows: $+0,0 \% ;+1$, $1-25 \%$; $+2,26-50 \%$; $+3,51-75 \%$; or $+4,>75 \%$. Intensity and proportion of stained cells were added for the Q score, which had a range of 0 to 7 . HER2 immunohistochemistry was assessed based on the ASCO-CAP guidelines. ${ }^{16} 3+$ (positive) is defined as uniform intense membrane staining of $>30 \%$ of invasive tumor cells; $2+$ (equivocal) is complete 
membranous staining that is either non-uniform or weak in intensity but with obvious circumferential distribution in at least $10 \%$ of cells; $1+$ (negative) is weak incomplete membranous staining in any proportion of tumor cells; and finally 0 (negative) is no staining. To avoid expression variability as a factor, $Q$ score $\geqslant 6$ for estrogen and progesteron receptors and strong complete circumferential staining $(3+)$ in $>90 \%$ of tumor cells for HER2 immunohistochemistry were required for the analyses. These markers were independently evaluated by two investigators (TK, HH).

\section{Fluorescence In Situ Hybridization}

Three- $\mu \mathrm{m}$ sections were cut for fluorescence in situ hybridization analysis and mounted on glass slides coated with silane (3-aminopropyltriethoxysilane; Sigma, St Louis, MO, USA). The sections were deparaffinized and pretreated to facilitate probe permeability using a Pretreatment Kit (Vysis; Downers Grove, IL) according to the manufacturer's instructions. Briefly, slides were heated overnight $\left(56^{\circ} \mathrm{C}\right)$ and dewaxed in xylene, air-dried, and treated with $0.2 \mathrm{M} \mathrm{HCl}$ for $20 \mathrm{~min}$ at room temperature. This was followed by incubation in $1 \mathrm{M}$ sodium thiocyanate in $2 \times \operatorname{SSC}(0.5 \mathrm{M} \mathrm{NaCl}, 0.015 \mathrm{M}$ sodium citrate $)$ at $80^{\circ} \mathrm{C}$ for $30 \mathrm{~min}$, rinsed, and digested with protease $(1.25 \mathrm{mg} / \mathrm{ml})$ for $30 \mathrm{~min}$ at $37^{\circ} \mathrm{C}$. The slides were finally dehydrated in an ethanol series (70$100 \%)$ and air-dried. ISH was performed using the PathVysion HER2 DNA Probe Kit (Vysis) basically according to the manufacturer's recommendations. The hybridization solution containing the probe was applied to the treated slides, the area coverslipped, and sealed. The slides were then placed in a slide thermocycler (Hybaid Omnislide) programmed to codenature probe, target DNA, and incubate the slides for hybridization $\left(75^{\circ} \mathrm{C} 5 \mathrm{~min}, 38^{\circ} \mathrm{C} 16 \mathrm{~h}\right.$, or overnight). Post-hybridization washes were performed $(0.5 \times \mathrm{SSC}, 0.1 \% \mathrm{NP}-40 \mathrm{pH} 7)$ at $70^{\circ} \mathrm{C}$ followed by counterstaining in DAPI $(0.1 \mathrm{~g} / \mathrm{ml}$ in $2 \times$ SSC) at room temperature. The slides were mounted with antifade (Vectashield) and viewed under an epifluorescence microscope (Olympus).

Staining was independently evaluated based on ASCO-CAP criteria by two investigators (TK, SS). Presence of any of the following made the specimen compromised for HER2 fluorescence in situ hybridization evaluation. 1. Vague cellular outline, 2. Nonuniform weak signal ( $>25 \%$ unscorable because of weak signal) 3. Non-optimal enzymatic digestion (poor nuclear resolution, autofluorescence), and 4. Background obscures signal ( $>10 \%$ of signal over cytoplasm). ${ }^{15}$

\section{Statistical Analyses}

Statistical analyses for pairwise comparison of groups (estrogen and progesterone receptors decline with time of delay to fixation for each case with the overall mean $Q$ score) were performed using the non-parametric sign test. Categorical variables (number of non-compromised cases for HER2 fluorescence in situ hybridization with time of delay of fixation) were analyzed using exact McNemar's test. A trend test (mean Q score decline of all cases combined for estrogen and progesterone receptors with time of delay of fixation) was performed using Page's L test. Statistical Analysis was performed using SAS Statistical analysis software version 9.1.3. A nominal significance level of 0.05 was used.

\section{Results}

\section{Overall Clinicopathologic Variables, Immunohistochemistry and Fluorescence In Situ Hybridization Results of Clinically Submitted Sections}

Pathological parameters and immunohistochemistry/ fluorescence in situ hybridization results are outlined in Table 1. Q score $\geqslant 6$ was identified in

Table 1 Clinicopathological findings with overall staining status and delay to formalin fixation effect on each case

\begin{tabular}{|c|c|c|c|c|c|c|c|c|c|c|}
\hline Case no. & 1 & 2 & 3 & 4 & 5 & 6 & 7 & 8 & 9 & 10 \\
\hline Tumor type & Ductal & Ductal & Ductal & Ductal & Ductal & Ductal & Ductal & Ductal & Ductal & Ductal \\
\hline Tumor grade (mSBR) & 2 & 3 & 1 & 3 & 3 & 3 & 3 & 1 & 3 & 3 \\
\hline Tumor size $(\mathrm{cm})$ & 2 & 2.2 & 1.8 & 2.1 & 3 & 1.4 & 1.4 & 1.9 & 2.3 & 2.3 \\
\hline Tumor stage (TN) & T1cNo & T2No & T1cNo & T2No & T2NX & T1cN1a & T1cN1a & T1cNo & T2N1a & T2No \\
\hline DCIS (\%) & 0 & 0 & 5 & 0 & 0 & 40 & 5 & 5 & 5 & 5 \\
\hline Patient age (years) & 44 & 50 & 41 & 63 & 52 & 45 & 48 & 62 & 54 & 60 \\
\hline $\mathrm{ER}^{*}$ & 3 & 0 & 7 & 0 & 0 & 7 & 0 & 7 & 7 & 7 \\
\hline $\mathrm{PR}^{*}$ & 0 & 0 & 6 & 0 & 0 & 7 & 0 & 7 & 0 & 7 \\
\hline HER2 $(\mathrm{IHC})^{\wedge}$ & 2 & 0 & 2 & 1 & 3 & 2 & 0 & 1 & 1 & 0 \\
\hline HER2 (FISH)** & 1.2 & 0.9 & 1.5 & 1.5 & $>20$ & 1 & 1.1 & 0.7 & 0.9 & 1.6 \\
\hline $\mathrm{DFF} \mathrm{ER}^{\wedge} \wedge$ & NA & NA & + & NA & NA & - & NA & - & - & + \\
\hline $\mathrm{DFF} \mathrm{PR}^{\wedge} \wedge$ & NA & NA & + & NA & NA & - & NA & - & NA & - \\
\hline DFF HER2 FISH^^${ }^{\wedge}$ & - & - & - & - & - & - & - & - & + & - \\
\hline
\end{tabular}

NA, not applicable (score <6); ${ }^{*} \mathrm{Q}$ score; $\wedge$ score based on ASCO-CAP guidelines (see Hillner and Smith ${ }^{15}$ ); ${ }^{*}$ HER2/Cep17 ratio; $\wedge \wedge$ Marker affected $(-)$ or not affected $(+)$ by DFF. mSBR, modified Scarff-Bloom-Richardson; DCIS, ductal carcinoma in situ; ER, Estrogen receptor; PR, progesterone receptor; IHC, immunohistochemistry; FISH, fluorescence in situ hybridization; DFF, delay to formalin fixation. 
Table 2 Delay to formalin fixation time and estrogen and progesterone receptors and HER2 fluorescence in situ hybridization

\begin{tabular}{|c|c|c|c|c|c|c|c|c|}
\hline \multirow[t]{2}{*}{ DFF time } & \multicolumn{3}{|c|}{$E R$} & \multicolumn{3}{|c|}{$P R$} & \multicolumn{2}{|c|}{ HER2 FISH } \\
\hline & $\begin{array}{c}\text { Mean } \\
Q \text { score(range) }\end{array}$ & $\begin{array}{l}\text { Mean difference in } \\
Q \text { score (range) }\end{array}$ & $P$-value* & $\begin{array}{c}\text { Mean } \\
Q \text { score (range) }\end{array}$ & $\begin{array}{l}\text { Mean difference in } \\
Q \text { score (range) }\end{array}$ & $P$-value ${ }^{*}$ & $\begin{array}{c}\text { No. of } \\
\text { valid cases }\end{array}$ & $P$-value** \\
\hline $0 \mathrm{~min}$ & $7(7-7)$ & $0(0-0)$ & NA & $6.75(6-7)$ & 0 & NA & 10 & NA \\
\hline $10 \mathrm{~min}$ & $7(7-7)$ & $0(0-0)$ & NA & $6.75(6-7)$ & 0 & NA & 10 & NA \\
\hline $30 \mathrm{~min}$ & $7(7-7)$ & $0(0-0)$ & NA & $6.75(6-7)$ & 0 & NA & 10 & NA \\
\hline $1 \mathrm{~h}$ & $7(7-7)$ & $0(0-0)$ & NA & $6(4-7)$ & 0.75 & NS & 7 & NS \\
\hline $2 \mathrm{~h}$ & $6.8(6-7)$ & $0.2(0-1)$ & NS & $6(4-7)$ & 0.75 & NS & 4 & $<0.03$ \\
\hline $4 \mathrm{~h}$ & $6.4(6-7)$ & $0.6(0-1)$ & NS & $6(4-7)$ & 0.75 & NS & 2 & $<0.008$ \\
\hline $8 \mathrm{~h}$ & $5.6(3-7)$ & $1.4(0-4)$ & NS & $5.75(4-7)$ & 1 & NS & 1 & $<0.004$ \\
\hline ON & $5.8(5-7)$ & $1.2(0-2)$ & NS & $5.25(3-7)$ & 1.5 & NS & 1 & $<0.004$ \\
\hline
\end{tabular}

NA, not applicable; NS, not significant; ER, Estrogen receptor; PR, progesterone receptor; FISH, fluorescence in situ hybridization;

${ }^{*} P$-values are obtained using the sign test.

${ }^{* *} P$-value obtained using exact McNemar's test.

five cases for estrogen receptor and four cases for progesterone receptor. HER2 immunohistochemistry was $3+$ in one case, which was amplified by fluorescence in situ hybridization (HER2/Cep17>20). The rest of the specimens were not amplified.

\section{Delay to Formalin Fixation and Estrogen and Progesterone Receptors Results}

The mean $\mathrm{Q}$ score started to decline at $2 \mathrm{~h}$ mark for estrogen receptor and $1 \mathrm{~h}$ mark for progesterone receptor. Lowest score was at $8 \mathrm{~h}$ mark for estrogen receptor and overnight for progesterone receptor (Table 2, Figures 1 and 2). Delay to formalin fixation appeared to have an effect on both the number/ percentage of positive cells and the intensity of the stain. These results were statistically insignificant (sign test and Page's L test). Q score of $>0$ and $<6$ was seen in one case (case no. 1) for estrogen receptor and none for progesterone receptor. This case had the following scores, 3 at $0 \mathrm{~min}, 10 \mathrm{~min}$, $30 \mathrm{~min}$ and $1 \mathrm{~h}, 2$ at $2 \mathrm{~h}, 4 \mathrm{~h}$ and overnight; and 0 at $8 \mathrm{~h}$ (Figure 3 ).

\section{Delay to Formalin Fixation and HER2 By Immunohistochemistry and Fluorescence In Situ Hybridization}

For HER2 immunohistochemistry, one case had $3+$ staining in $>90 \%$ of the tumor cells. Delay to formalin fixation had no effect on this case (Figures 4a and c). HER2 expression and its strong double membrane feature useful for HER2 overexpression evaluation were not affected. Cases that scored $2+$ or $1+$ had variable and inconsistent results due to tissue microarray sampling variability (data not shown).

Using ASCO-CAP criteria, delay to formalin fixation up to $30 \mathrm{~min}$ had no effect on HER2 fluorescence in situ hybridization interpretation (Figures 4b and 5a). There were seven cases noncompromised after $1 \mathrm{~h}$, four cases after $2 \mathrm{~h}(P<0.03)$, two cases after $4 \mathrm{~h}(P<0.008)$, and one case after $8 \mathrm{~h}$ and one case when the specimen was stored overnight $(P<0.004)$ (Table 2). The compromised specimens had at least one of the following, vague cellular outline, non-uniform weak signal ( $>25 \%$ unscorable due to weak signal) and/or poor nuclear resolution (Figures $4 \mathrm{~d}$ and $5 \mathrm{~b}$ ). None of the samples were compromised due to background obscuring signal (signal over cytoplasm). We found that the most critical compromising factor that affected HER2 fluorescence in situ hybridization test was non-uniform signal. Interestingly, we found that the HER2 signal (orange) but not the chromosome 17 centromere signal (green) was weaker/faded with delay to fixation. Figure 5 illustrated this finding very well. Figures $5 \mathrm{~b}$ and $\mathrm{d}$ were taken from case number 2 at 0 min and $4 \mathrm{~h}$ respectively. HER2/Cep17 reading at $0 \mathrm{~min}$ was $86 / 88(0.98)$, whereas this reading at $4 \mathrm{~h}$ was $28 / 96(0.29)$. There was a total of 35 of 80 samples that were compromised for interpretation. Twenty-two of 34 samples were compromised for two or more reasons. Although poor nuclear resolution was the affecting factor in 24 samples, vague cellular outline and non-uniform signal were the affecting factors in 18 and 19 samples, respectively (Table 3). For each case, there seem to be a consistent reason(s) that compromises HER2 fluorescence in situ hybridization. No consistency in the reason of the compromised cases with regard to time of fixation.

\section{Discussion}

Accurate and reliable assessment of the estrogen and progesterone receptors and HER2 status of invasive breast cancers is crucial for the therapeutic decision making. Results from these tests help guide the choice of treatment options for women with breast cancer. Estrogen and progesterone receptor status are used routinely to determine if a patient will benefit from endocrine therapy. The use of endocrine therapy for breast cancer treatment has been shown to have a dramatic impact on improving 
a
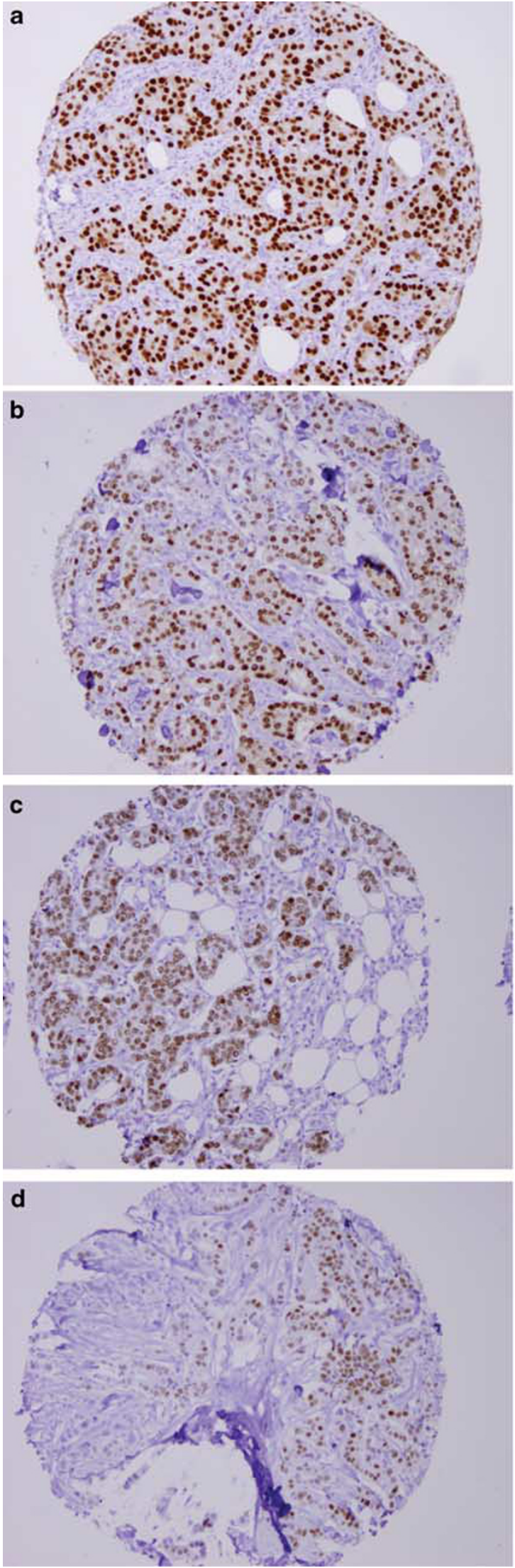
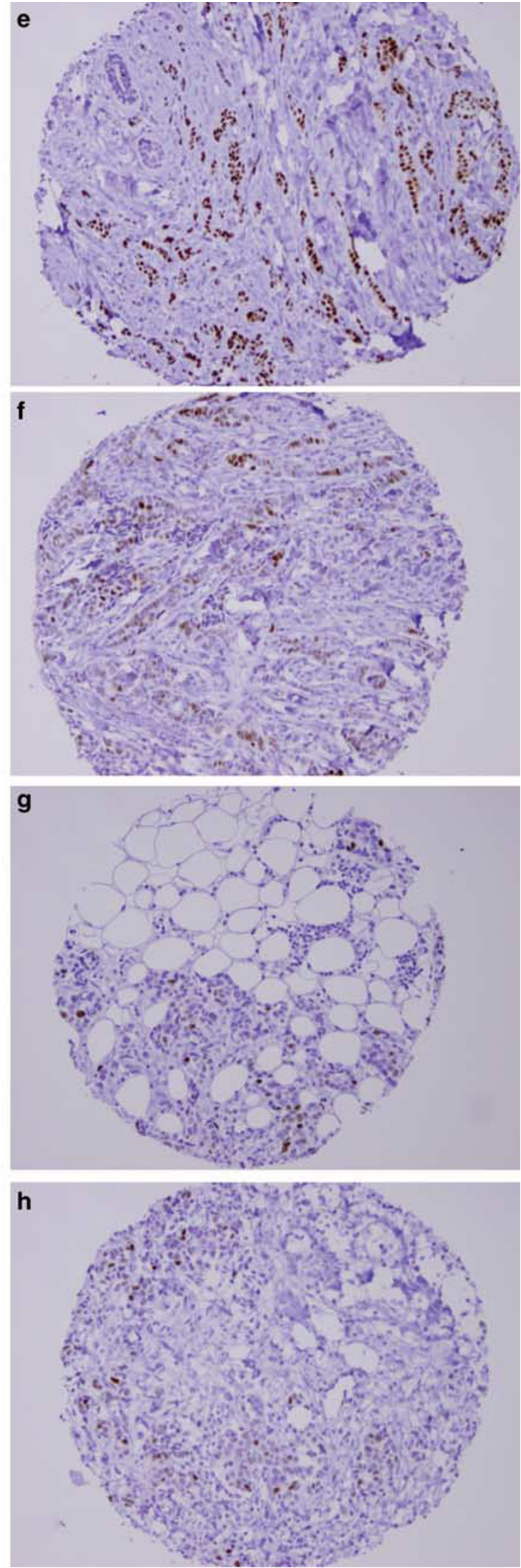

Figure 1 Estrogen receptor expression in case number 9; a, $0 \mathrm{~min} ; \mathbf{b}, 4 \mathrm{~h} ; \mathbf{c}, 8 \mathrm{~h}$; d, overnight. Progesterone receptor expression in case number 8; e, $0 \mathrm{~min} ; \mathbf{f}, 1 \mathrm{~h} ; \mathbf{g}, 4 \mathrm{~h} ; \mathbf{h}, 8 \mathrm{~h}(\times 100)$. Note decreased markers expression and intensity with the time of delayed fixation. 


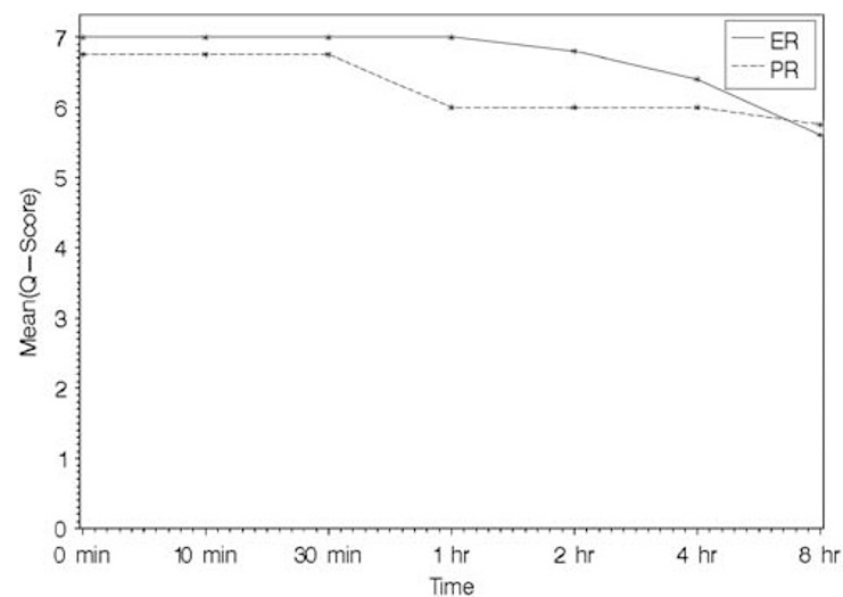

Figure 2 Mean Q score decline for estrogen and progesterone receptors with relation to time of fixation. Not statistically significant using Page's L test.

disease-free survival and overall survival. ${ }^{22} \mathrm{~A}$ negative result might suggest that the patient would benefit from cytotoxic chemotherapy alone or indicate that the patient requires no systemic therapy. Trastuzumab is given to patients who are found to have overexpression of HER2. In those patients with HER2 overexpression, use of Trastuzumab has resulted in a significant improvement in disease-free survival and overall survival, so accurate identification of these patients is of utmost importance. $^{23}$

Although it is accepted that hormone receptornegative patients should not be considered for endocrine therapy, many studies show that a proportion of these patients do respond to such treatment. ${ }^{24}$ Similarly, it is recommended that only patients with HER2-amplified tumors should be considered for target therapy with Trastuzumab. However, some recent studies have shown that a proportion of HER2-negative patients could benefit from this therapy as well. ${ }^{25}$

A positive response to endocrine therapy in estrogen and progesterone receptor-negative patients could be explained by a false-negative hormone receptor assay in the breast excisional specimens. This prompted some investigators to study the actual variability between needle-core biopsy and mastectomy specimens by immunohistochemistry or ligand-binding assay methods. ${ }^{20,26-29}$ Mann et $a l^{20}$ found that in $13 \%$ of cases, the core biopsy was estrogen receptor positive, whereas the surgical specimen was estrogen receptor negative. In addition, they found that in $11 \%$ of the cases, the core biopsy specimens showed some progesterone receptor staining, whereas the surgical specimen showed no staining. Possible reasons for this discrepancy may include sampling error, with the core biopsy not reflecting the status of the entire tumor. Another possibility is the fixation artifact because of the delay in exposure of the center of a surgical specimen to formalin. Owing to the retrospective nature of the study, this possibility could not be further investigated. The studied sample was not uniformly processed. The time of incising, before or after fixation, was made based on the sample size. Also, some specimens were held without fixation in order to procure tissue. ${ }^{20}$

We, therefore, intended to clarify the second possibility. We created an experimental model resembling the ischemic environment of the tumor cells when left unfixed. To achieve uniformity among all tested specimens, careful prospective design was achieved. All women had uniform surgery procedure (lumpectomy without post-surgery X-ray), had no neoadjuvant therapy, and their specimens received shortly (within $5 \mathrm{~min}$ ) after surgery. To avoid prolonged fixation as a factor, surgeries were scheduled roughly at the same time (within $1 \mathrm{~h}$ difference). All specimens were promptly inked and dissected in the same manner. All samples uniformly immersed in the same environment $(0.9 \% \mathrm{NaCL}$, to resemble the fluid around tumor cells and lack of oxygen, in room temperature) before transferring tissue to formalin. The proportion of sample size and formalin size was constant among all samples. All samples were then loaded at the same time in the tissue processor. They all had a fixation time between 12 and $32 \mathrm{~h}$. With this carefully designed model, we were able to evaluate the ischemic effect on tumor biomarkers. We found that the expression of estrogen and progesterone receptors declined with progressive ischemia. These findings are consistent with others. $^{21,30}$ Wasielewski et $a l^{21}$ evaluated the effect of fixation on estrogen and progesterone receptors analyses in three cases. They found that immunoreactivity was most affected by a delay to formalin fixation for $12 \mathrm{~h}$ with relative expression of estrogen and progesterone receptors decreasing from $100 \%$ each to 61.2 and $40.4 \%$, respectively. Ellis et $a l^{30}$ studied the effect of progressive ischemia on hormone receptor analyses. Protein level was determined by ligand-binding assay developed by Bradford. ${ }^{31}$ They found that the ischemia decreased estrogen receptor levels in $30 \mathrm{~min}$, whereas progesterone receptor levels were unchanged through 150 min of ischemia. It is known that formaldehyde immediately produces reactive hydroxymethyl groups on amino acids that cross-link proteins and large molecules that are necessary for immunohistochemistry analysis. ${ }^{32-34}$ Moreover, proteolysis often causes nonspecific binding to unrelated molecules. ${ }^{35}$ These factors are most likely the reason behind decreased estrogen and progesterone receptor expression with tumor ischemia. In our study, the estrogen receptor started to decline at a $2 \mathrm{~h}$ mark and progesterone receptor at a $1 \mathrm{~h}$ mark. Although these findings are not statistically significant, the breast cancer biomarker score decrease by itself is significant, as the prognosis will change from relatively good (with score of 6 or 7 ) to intermediate 

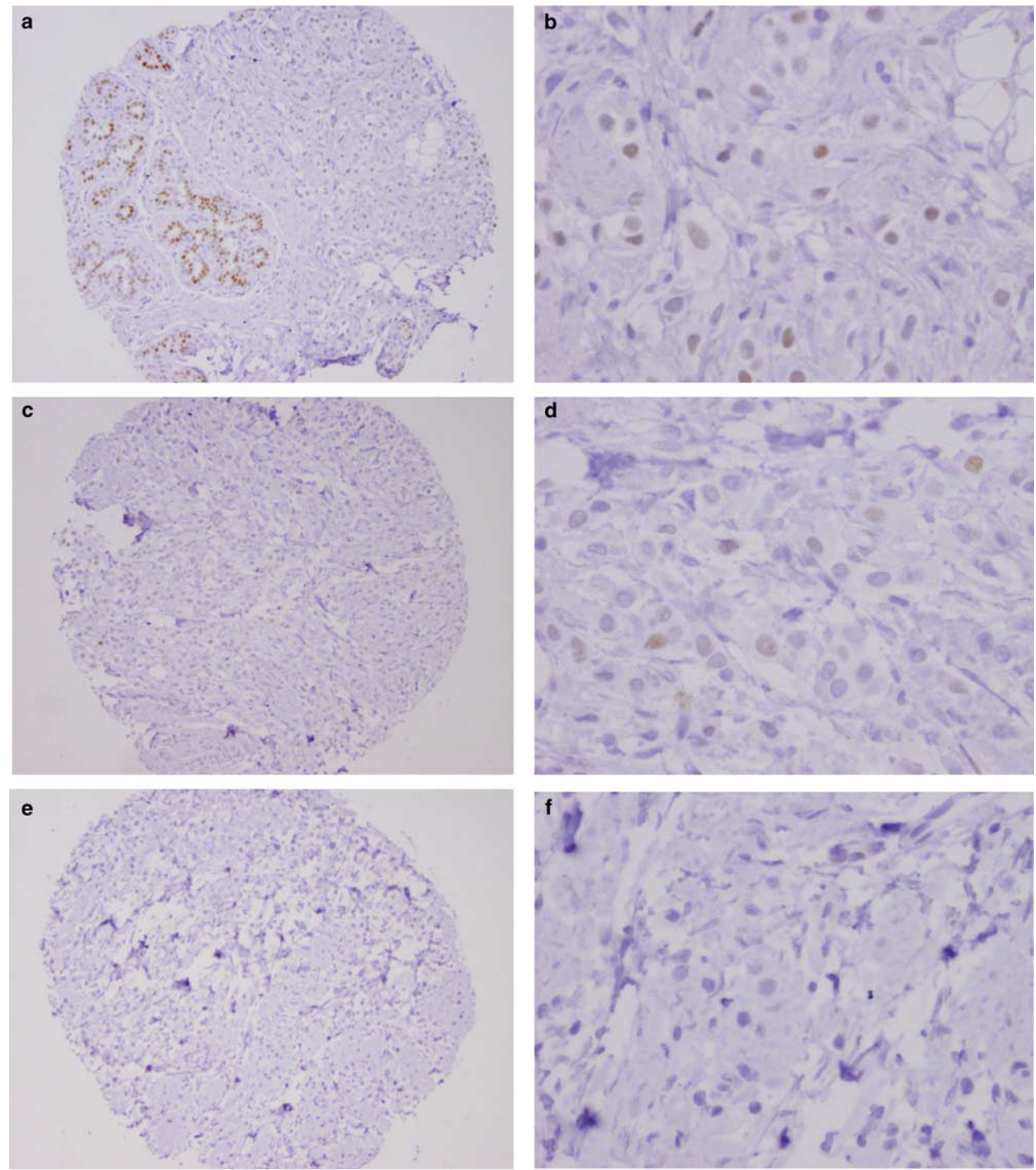

Figure 3 Estrogen receptor expression in case no. 1; a and b, 0 min with Q score 3; $\mathbf{c}$ and $\mathbf{d}, 2 \mathrm{~h}$ with Q score 2; e and f, $8 \mathrm{~h}$ with Q score 0. a, $\mathbf{c}$ and $\mathbf{e}(\times 100)$; b, $\mathbf{d}$ and $\mathbf{f}(\times 400)$. Note decreased number of positive cells with the time of delayed fixation.

(with score of 4 or 5 ). ${ }^{36}$ Estrogen and progesterone receptor status conversion from positive to negative could theoretically happen. An example of such a scenario could be seen in case no. 1 , as samples $2 \mathrm{~h}$, $4 \mathrm{~h}$ and overnight had a $\mathrm{Q}$ score of 2 and sample $8 \mathrm{~h}$ had a Q score of 0 . If a cutoff $>2$ was used to define positive expression, estrogen receptor status was actually converted from positive to negative because of the delay to formalin fixation. Moreover, sample $8 \mathrm{~h}$ was completely negative. One very important point that should be raised is that this change might be due to the nature of selection of tissue by the tissue microarray technique. This finding could, therefore, explain the discrepancy that Mann et $a l^{20}$ 

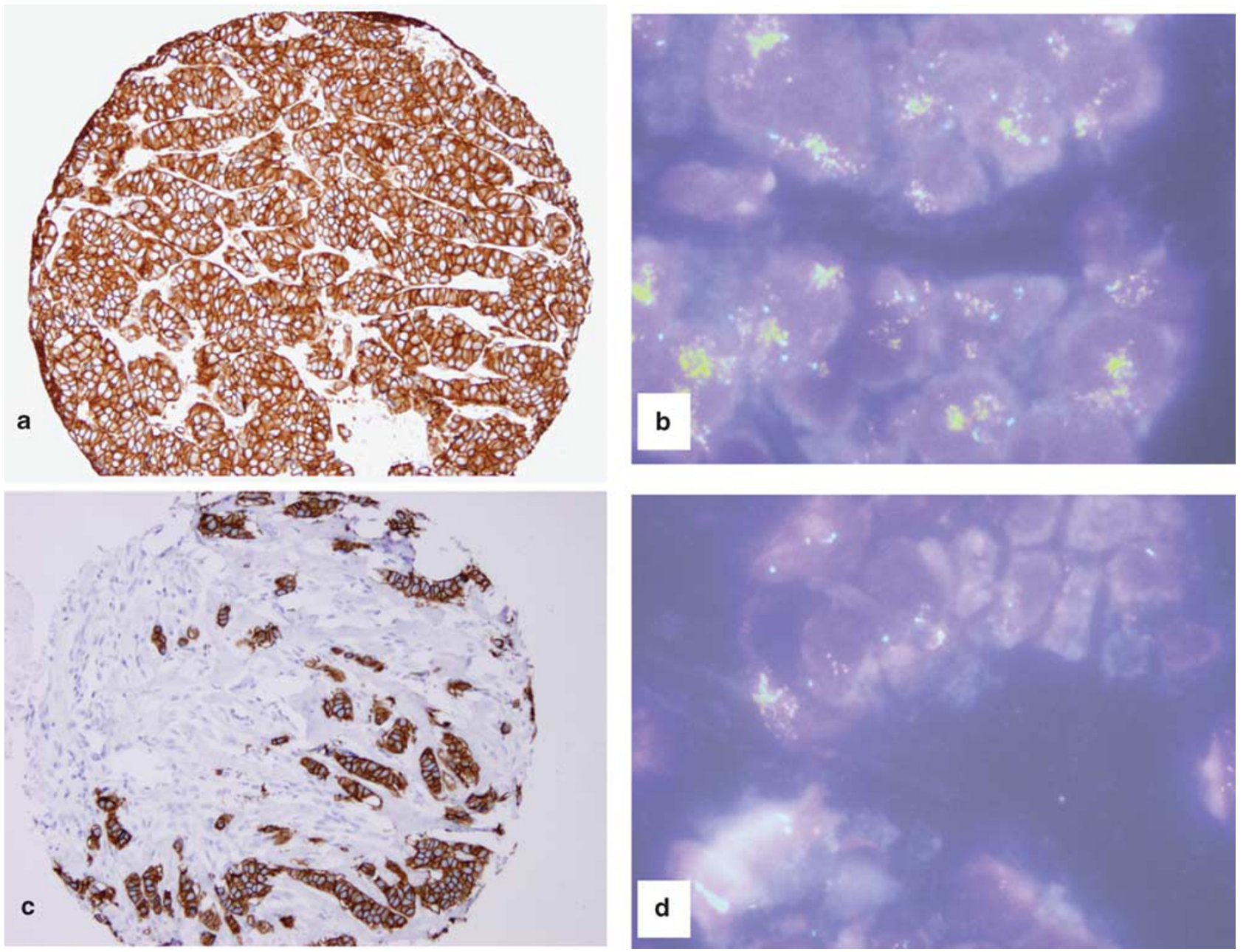

Figure 4 HER2 immunohistochemistry $(\times 100)$ and HER2 fluorescence in situ hybridization $(\times 1000)$ in case number 5 ; a, 30 min IHC; b, 30 min fluorescence in situ hybridization; c, 2 h immunohistochemistry; $\mathbf{d}, 2 \mathrm{~h}$ fluorescence in situ hybridization. Note that delay to formalin fixation had no effect on HER2 immunohistochemistry. The corresponding fluorescence in situ hybridization sections show non-uniform signal when delay to formalin fixation is $2 \mathrm{~h}$.

and others found between needle-core biopsy and mastectomy specimens. We, therefore, agree with the 'Ad hoc' first recommendation to fix tissue as soon as possible within $1 \mathrm{~h}^{4}{ }^{4}$ We add, however, specimens should not be stored overnight at $4^{\circ} \mathrm{C}$.

Understanding why patients who are found to have HER2-negative tumors respond to Trastuzumab is more complex. Hybridization efficacy and tissue morphology are usually negatively correlated. Aggressive pretreatment procedures improving hybridization efficacy tend to destroy the cell structure and tissue morphology. However, mild pretreatment saving tissue structures may not be sufficient for probe penetration and successful fluorescence in situ hybridization results. Many problems can arise in fluorescence in situ hybridization procedure including prolonged storage, tissue loss, tissue autofluorescence and poor tissue morphology. The latter may include prolonged fixation that exceeds $24 \mathrm{~h}$ or insufficient fixation and autolysis. Dim signal may be because of poor digestion, low probe concentration, poor hybridization conditions or loss of DNA. ${ }^{37}$ In our experimental model, we intended to dissect the process and stain all samples uniformly to eliminate these as factors affecting our results. A previous study that examined optimizing autopsy tissue concluded that Vysis pretreatment kit, like in our method, can improve tissue morphology and nuclei. ${ }^{38}$ As our results showed, using this kit is not enough to overcome preanalytical delay to formalin-fixation artifacts that are included in ASCO-CAP criteria. Our study is the first to evaluate delay to formalin-fixation effect on HER2 fluorescence in situ hybridization. We found that specimen should be fixed within $1 \mathrm{~h}$ to comply with the ASCO-CAP criteria. One important finding was that the non-uniform signal was because of the dim or absent HER2 signal rather than the centromere signal. The reason behind this finding is unclear. However, given the uniformity of tissue 

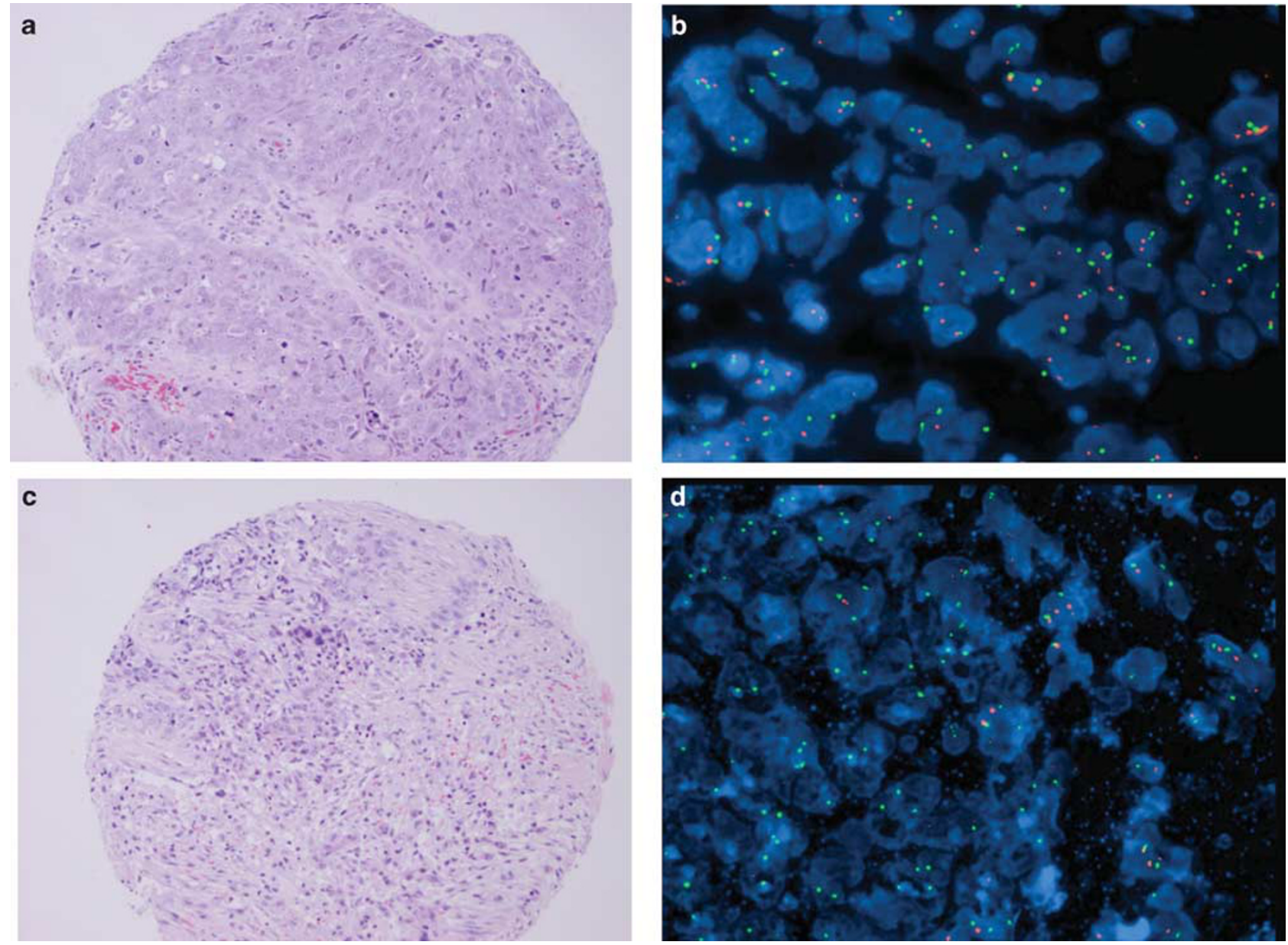

Figure 5 HER2 fluorescence in situ hybridization with corresponding H\&E sections in case number 2; a and b, 0 min; c and d, $4 \mathrm{~h}$; $(\times 1000)$. For fluorescence in situ hybridization, comparing with 0 min that is non-compromised for interpretation, $\mathbf{d}$ shows a vague cellular outline, poor nuclear resolution and faded non-uniform signal in $>75 \%$ of cells. Note faded HER2 (orange) signal more than chromosome 17 centromere (green) signal. The HER2/Cep 17 score for $\mathrm{B}=0.98$ and for $\mathrm{D}=0.29$. For H\&E, note decrease in the quality of tissue preservation and increased autolysis in $\mathbf{c}$ compared with a.

Table 3 Delay to formalin fixation time and HER2 by fluorescence in situ hybridization

\begin{tabular}{|c|c|c|c|c|c|c|c|c|c|}
\hline Case no. & $0 \min$ & $10 \mathrm{~min}$ & $30 \mathrm{~min}$ & $1 \mathrm{~h}$ & $2 h$ & $4 h^{\prime}$ & $8 h$ & Overnight & Total compromised ${ }^{\wedge}$ \\
\hline 1 & + & + & + & + & A,C & $\mathrm{C}$ & $\mathrm{A}, \mathrm{C}$ & $\mathrm{A}, \mathrm{C}$ & 4 \\
\hline 2 & + & + & + & + & $\mathrm{A}, \mathrm{B}, \mathrm{C}$ & $\mathrm{A}, \mathrm{B}, \mathrm{C}$ & $\mathrm{A}, \mathrm{B}, \mathrm{C}$ & $\mathrm{A}, \mathrm{B}, \mathrm{C}$ & 4 \\
\hline 3 & + & + & + & + & + & $\mathrm{C}$ & $\mathrm{C}$ & $\mathrm{C}$ & 3 \\
\hline 4 & + & + & + & $\mathrm{C}$ & C & $\mathrm{C}$ & $\mathrm{C}$ & $\mathrm{C}$ & 5 \\
\hline 5 & + & + & + & $\mathrm{C}$ & $\mathrm{B}, \mathrm{C}$ & $\mathrm{B}, \mathrm{C}$ & $\mathrm{B}, \mathrm{C}$ & $\mathrm{B}, \mathrm{C}$ & 5 \\
\hline 6 & + & + & + & + & + & $\mathrm{C}$ & $\mathrm{C}$ & $\mathrm{C}$ & 3 \\
\hline 7 & + & + & + & + & A,B & A,B & A,B & $\mathrm{A}, \mathrm{B}$ & 4 \\
\hline 8 & + & + & + & A,B & A,B & A,B & A,B & A,B & 5 \\
\hline 9 & + & + & + & + & + & + & + & + & 0 \\
\hline 10 & + & + & + & + & + & + & A,B & A,B & 2 \\
\hline Total compromised ${ }^{\wedge}$ & + & + & + & 3 & 6 & 8 & 9 & 9 & 35 \\
\hline
\end{tabular}

+ , non-compromised for evaluation; any letter, compromised for evaluation, 'A' due to vague cellular outline, 'B' due to non-uniform signal (dim or absence of orange signal), and 'C' due to poor nuclear resolution; ^, total number of samples that were invalid at certain time (vertical) and for each case (horizontal).

preparation, the following factors including poor digestion, low probe concentration or poor hybridization conditions could be excluded. ${ }^{37}$ Therefore, one possibility might be related to variability of DNA resistance to autolysis. It appears that DNA at the centromere locus might be more resistant to 
autolysis than the HER2 gene locus and thus hybridizes better with the FISH probe. This is crucial when interpreting HER2 fluorescence in situ hybridization, as this scenario will falsely undercount the HER2 signal and eventually will convert a tumor from amplified for HER2 to non-amplified, particularly in the borderline cases. Only one case had amplified HER2 detected by both immunohistochemistry and fluorescence in situ hybridization. Comparing fluorescence in situ hybridization with immunohistochemistry, the latter was a more robust method (immunohistochemistry maintained its positivity at all stages of ischemia). However, a larger cohort is needed to verify this observation. For the laboratories that use fluorescence in situ hybridization as the sole method to detect HER2 status, we suggest performing HER2 immunohistochemistry as well. Another interesting finding from our study is that overnight storage at $4^{\circ} \mathrm{C}$ is similar to leaving specimen without fixation for $8 \mathrm{~h}$. Therefore, we recommend immediate specimen delivery to the pathology department for processing fixation.

In conclusion, delay to formalin fixation has a crucial negative effect on HER2 fluorescence in situ hybridization testing. Our results are consistent with 'Ad hoc' committee recommendation of fixing a tissue within $1 \mathrm{~h}$ of surgery. We, however, recommend not storing a tissue overnight at $4^{\circ} \mathrm{C}$, as this has a negative effect on all biomarkers.

\section{Disclosure/conflict of interest}

The authors declare no conflict of interest.

\section{References}

1 Alberts SR, Ingle JN, Roche PR, et al. Comparison of estrogen receptor determinations by a biochemical ligand binding assay and immunohistochemical staining with monoclonal antibody ER1D5 in females with lymph node positive breast carcinoma entered on two prospective clinical trials. Cancer 1996;78: 764-772.

2 Barnes DM, Harris WH, Smith P, et al. Immunohistochemical determination of oestrogen receptor: comparison of different methods of assessment of staining and correlation with clinical outcome of breast cancer patients. Br J Cancer 1996;74:1445-1451.

3 Barnes DM, Millis RR, Beex LV, et al. Increased use of immunohistochemistry for oestrogen receptor measurement in mammary carcinoma: the need for quality assurance. Eur J Cancer 1998;34:1677-1682.

4 Yaziji H, Taylor CR, Goldstein NS, et al. Consensus recommendations on estrogen receptor testing in breast cancer by immunohistochemistry. Appl Immunohistochem Mol Morphol 2008;16:513-520.

5 Bast Jr RC, Ravdin P, Hayes DF, et al. 2000 update of recommendations for the use of tumor markers in breast and colorectal cancer: clinical practice guidelines of the American Society of Clinical Oncology. J Clin Oncol 2001;19:1865-1878.
6 Vogel CL, Franco SX. Clinical experience with trastuzumab (Herceptin). Breast J 2003;9:452-462.

7 Baselga J, Norton L, Albanell J, et al. Recombinant humanized anti-HER2 antibody (Herceptin) enhances the antitumor activity of paclitaxel and doxorubicin against HER2/neu overexpressing human breast cancer xenografts. Cancer Res 1998;58:2825-2831.

8 Pegram MD, Slamon DJ. Combination therapy with

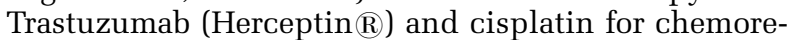
sistant metastatic breast cancer: evidence for receptorenhanced chemosensitivity. Semin Oncol 1999;26: 89-95.

9 Slamon DJ, Godolphin W, Jones LA, et al. Studies of the HER-2/neu proto-oncogene in human breast and ovarian cancer. Science 1989;244:707-712.

10 Borg A, Tandon AK, Sigurdsson H, et al. HER-2/neu amplification predicts poor survival in nodepositive breast cancer. Cancer Res 1990;50:4332-4337.

11 Parkes HC, Lillycrop K, Howell A, et al. C-erbB2 mRNA expression in human breast tumours: comparison with c-erbB2 DNA amplification and correlation with prognosis. Br J Cancer 1990;61:39-45.

12 Slamon DJ, Clark GM, Wong SG, et al. Human breast cancer: correlation of relapse and survival with amplification of the HER-2/neu oncogene. Science 1987;253:177-182.

13 Telli ML, Hunt SA, Carlson RW, et al. Trastuzumabrelated cardiotoxicity: callin into question the concept of reversibility. J Clin Oncol 2007;25:3525-3533.

14 Tan-Chiu E, Yothers G, Romond E, et al. Assessment of cardiac dysfunction in a randomized trial comparing doxorubicin and cyclophosphamide followed by paclitaxel, with or without trastuzumab as adjuvant therapy in node-positive, human epidermal growth factor receptor 2-overexpressing breast cancer: NSABP B-31. J Clin Oncol 2005;23:7811-7819.

15 Hillner BE, Smith TJ. Do the large benefits justify the large costs of adjuvant breast cancer trastuzumab? J Clin Oncol 2007;25:611-613.

16 Wolff AC, Hammond ME, Schwartz JN, et al. American Society of Clinical Oncology/College of American Pathologists Guideline Recommendations for human epidermal growth factor receptor 2 testing in breast cancer. Arch Pathol Lab Med 2007;131:18-43.

17 Goldstein NS, Ferkowicz M, Odish E, et al. Minimum formalin fixation time for consistent estrogen receptor immunohistochemical staining of invasive breast carcinoma. Am J Clin Pathol 2003;120:86-92.

18 Arber DA. Effect of prolonged formalin fixation on the immunohistochemical reactivity of breast markers. Appl Immunohistochem \& Molec Morphol 2002; 10:183-186.

19 Selvarajan S, Bay BH, Choo A, et al. Effect of fixation period on HER2/neu gene amplification detected by fluorescence in situ hybridization in invasive breast carcinoma. J Histochem \& Cytochem 2002;50: 1693-1696.

20 Mann GB, Fahey VD, Feleppa F, et al. Reliance on hormone receptor assays of surgical specimens may compromise outcome in patients with breast cancer. J Clin Oncol 2005;23:5148-5154.

21 von Wasielewski $\mathrm{R}$, Mengel $\mathrm{M}$, Nolte $\mathrm{M}$, et al. Influence of fixation, antibody clones and signal amplification on steroid receptor analysis. Breast J 1998;4:33-40.

22 Fisher B, Costantino J, Redmond C, et al. A randomized clinical trial evaluating tamoxifen in the 
treatment of patients with nodenegative breast cancer who have estrogen-receptor-positive tumors. N Engl J Med 1989;320:479-484.

23 Goldhirsch A, Wood WC, Gelber RD, et al. Meeting highlights. Updated international expert consensus on the primary therapy of early breast cancer. J Clin Oncol 2003;21:3357-3365.

24 Barnes DM, Millis RR, Beex LV, et al. Increased use of immunohistochemistry for oestrogen receptor measurement in mammary carcinoma: The need for quality assurance. Eur J Cancer 1998;34:1677-1682.

25 Paik S, Kim C, Wolmark N. HER2 status and benefit from adjuvant Trastuzumab in breast cancer. N Engl J Med 2008;358:1409-1411.

26 Newsome JF, Avis FP, Hammond JE, et al. Sampling procedures in estrogen receptor determinations. Ann Surg 1981;193:549-554.

27 Hasson J, Luhan PA, Kohl MW. Comparison of estrogen receptor levels in breast cancer samples from mastectomy and frozen section specimens. Cancer 1981;47:138-139.

28 Teicher I, Tinker MA, Auguste LJ, et al. Effect of operative devascularization on estrogen and progesterone receptor levels in breast cancer specimens. Surgery 1985;98:784-791.

29 Young SC, Burkett RJ, Stewart C. Discrepancy in ER levels of breast carcinoma in biopsy vs mastectomy specimens. J Surg Oncol 1985;29:54-56.

30 Ellis LM, Wittliff JL, Bryant MS, et al. Lability of steroid hormone receptors following devascularization of breast tumors. Arch Surg 1989;124:39-42.
31 Bradford MM. A rapid and sensitive method for quantification of microgram quantities of proteins utilizing the principal of proteins-dye binding. Annal Biochem 1976;72:248-254.

32 Puchtler H, Meloan SN. On the chemistry of formaldehyde fixation and its effects on immunohistochemical reactions. Histochemistry 1985;82: 201-204.

33 Tome Y, Hirohashi S, Noguchi M, et al. Preservation of cluster 1 small cell lung cancer antigen in zincformalin fixative and its application to immunohistological diagnosis. Histopathology 1990;16: 469-474.

34 Eltoum I, Fredenburgh J, Myers RB, et al. Introduction to the theory and practice of fixation of tissues. J Histotechnol 2001:24:173-190.

35 Werner M, Chott A, Fabiano A, et al. Effect of formalin tissue fixation and processing on immunohistochemistry. Am J Surg Pathol 2000;24:1016-1019.

36 Harvey JM, Clark GM, Osborne CK, et al. Estrogen receptor status by immunohistochemistry is superior to the ligand-binding assay for predicting response to adjuvant endocrine therapy in breast cancer. J Clin Oncol 1999;17:1474-1481.

37 Harad Rider, et al.\#\#In: Rautenstraub BW Liehr T (eds) FISH book FISH Technology 1st edn. Springer: New York, 2002, pp 157.

38 Petersen BL, Sorensen M, Pedersen M, et al. Fluorescence in situ hybridization on formalin-fixed and paraffin-embedded tissue. Appl Immunohistochem Mol Morphol 2004;12:259-265. 